\title{
Association between executive and food functions in the acute phase after stroke
}

\author{
Associações entre função executiva e habilidade de alimentação pós-AVC na fase aguda \\ Aline Mansueto Mourão ${ }^{1,2}$, Laélia Cristina Caseiro Vicente², Mery Natali Silva Abreu³, Tatiana Simões \\ Chaves', Romeu Vale Sant'Anna ${ }^{4}$, Marcela Aline Fernandes Braga ${ }^{1}$, Fidel Castro Alves de Meira ${ }^{4}$, Leonardo \\ Cruz de Souza ${ }^{5}$, Aline Silva de Miranda ${ }^{6}$, Milene Alvarenga Rachid7?, Antônio Lucio Teixeira ${ }^{5}$
}

\begin{abstract}
Purpose: To investigate potential associations among executive, physical and food functions in the acute phase after stroke. Methods: This is a cross-sectional study that evaluated 63 patients admitted to the stroke unit of a public hospital. The exclusion criteria were other neurological and/or psychiatric diagnoses. The tools for evaluation were: Mini-Mental State Examination and Frontal Assessment Battery for cognitive functions; Alberta Stroke Program Early CT Score for quantification of brain injury; National Institutes of Health Stroke Scale for neurological impairment; Modified Rankin Scale for functionality, and the Functional Oral Intake Scale for food function. Results: The sample comprised 34 men (54\%) and 29 women with a mean age of 63.6 years. The Frontal Assessment Battery was significantly associated with the other scales. In multivariate analysis, executive function was independently associated with the Functional Oral Intake Scale. Conclusion: Most patients exhibited executive dysfunction that significantly compromised oral intake.
\end{abstract}

Keywords: stroke; cognitive dysfunction; cognition.

\section{RESUMO}

Objetivo: Investigar potenciais associações entre funções executiva, física global e de alimentação na fase aguda do acidente vascular cerebral (AVC). Métodos: Trata-se de estudo transversal envolvendo 63 pacientes admitidos em unidade de AVC de um hospital público. Os critérios de exclusão foram outros diagnósticos neurológicos e/ou psiquiátricos. Os instrumentos utilizados foram: Mini-Exame do Estado Mental e Bateria de Avaliação Frontal para avaliar funções cognitivas; Alberta Stroke Program Early CT Score para quantificação da lesão cerebral; National Institutes of Health Stroke Scale para comprometimento neurológico; Escala Modificada de Rankin para funcionalidade e Functional Oral Intake Scale para função alimentar. Resultados: A amostra compreendeu 34 homens e 29 mulheres, sendo a idade média de 63,6 anos. A Bateria de Avaliação Frontal correlacionou significativamente com as demais escalas. Na análise multivariada, a variável independentemente associada com a função executiva foi a Functional Oral Intake Scale. Conclusão: A maioria dos pacientes com AVC apresenta alterações das funções executivas que comprometem significativamente a alimentação oral.

Palavras-chave: acidente vascular cerebral; disfunção cognitiva; cognição.

The impairment of executive function is a common and often neglected symptom in the acute phase of the ischemic stroke $^{1,2,3,4}$. Approximately $50 \%$ of patients have impairment in one or more executive function domains in the first weeks after the stroke $e^{5,6,7,8}$.

The relationship between executive function and physical function has been poorly investigated in stroke, and most studies in this regard have been dedicated to its chronic phase $^{9,10}$. Changes in the domains of conceptualization, mental flexibility and programming can influence motor or physical performance and activities of daily living of patients even six months after the stroke ${ }^{3}$.

To date, only a few cognitive functions have been investigated in relation to oral food intake in stroke patients, including spatial and time orientation, immediate and evocative memory, and language $e^{11,12,13,14,15,16,17}$. As executive function

\footnotetext{
${ }^{1}$ Universidade Federal de Minas Gerais, Hospital Risoleta Tolentino Neves, Setor da Unidade de Acidente Vascular Cerebral, Belo Horizonte MG, Brasil;

2 Universidade Federal de Minas Gerais, Faculdade de Medicina, Departamento de Fonoaudiologia, Belo Horizonte MG, Brasil;

${ }^{3}$ Universidade Federal de Minas Gerais, Departamento de Enfermagem Aplicada, Belo Horizonte MG, Brasil;

4 Universidade Federal de Minas Gerais, Hospital Risoleta Tolentino Neves, Departamento de Neurologia, Unidade de Acidente Vascular Encefálico, Belo Horizonte MG, Brasil;

${ }^{5}$ Universidade Federal de Minas Gerais, Faculdade de Medicina, Departamento de Clínica Médica, Belo Horizonte MG, Brasil;

${ }^{6}$ Universidade Federal de Minas Gerais, Instituto de Ciências Biológicas, Departamento de Morfologia, Belo Horizonte MG, Brasil;

${ }^{7}$ Universidade Federal de Minas Gerais, Instituto de Ciências Biológicas, Departamento de Patologia Geral, Belo Horizonte MG, Brasil;

Correspondence: Aline Mansueto Mourão; Departamento de Fonoaudiologia da Faculdade de Medicina da UFMG; Avenida Professor Alfredo Balena, 190;

30130-100; Belo Horizonte MG, Brasil; E-mail:alinemmourao@gmail.com.br

Support: This study was funded by FAPEMIG - Fundação de Amparo à Pesquisa do Estado de Minas Gerais [grant number APQ-03539-13].

Conflict of Interest: There is no conflict of interest to declare.
}

Received 06 August 2017; Received in final form 03 November 2017; Accepted 28 November 2017. 
encompasses a set of skills such as planning and controlling the execution of complex tasks, including food intake, its evaluation could provide meaningful information for the management of patients with dysphagia.

The purpose of this study was to investigate the associations between executive function, overall motor performance and oral food intake in post-stroke patients during the acute phase of the disease.

\section{METHODS}

\section{Participants}

Patients who were admitted from January to June 2015 at the stroke unit of the Risoleta Tolentino Neves Hospital in Belo Horizonte, Minas Gerais, were eligible for this study. The inclusion criteria were patients over 18 years old with a diagnosis of ischemic stroke and an ictus time of up to 24 hours. The exclusion criteria were patients with a diagnosis of ischemic stroke in the brainstem region, transient ischemic attack or other neurological diseases, including dementia and Parkinson's disease. Patients with an altered level of consciousness and aphasia were also excluded.

The study was conducted in accordance with Resolution 466/2012. The project was evaluated and approved by the Research Ethics Committee of the Federal University of Minas Gerais, Project: CAAE - 32809514.4.4.0000.5149 of 11/09/2014.

\section{Assessment tools}

The tools for assessment of the cognitive functions were the Mini-Mental State Examination (MMSE) ${ }^{18}$ and the Frontal Assessment Battery (FAB $)^{19,20}$. The FAB was originally developed to be used as a short bedside instrument to assess frontal lobe functions, including six tests for exploring conceptualization, mental flexibility, motor programming, sensitivity to interference, inhibitory control, and environmental autonomy ${ }^{19}$.

The Alberta Stroke Program Early CT Score ${ }^{21}$ and the Oxfordshire Community Stroke Project were used for quantification and topographical characterization of the stroke, respectively. For the measurement of neurological impairment, the National Institutes of Health Stroke Scale (NIHSS) ${ }^{22}$ was used.

The modified Rankin Scale (mRS) ${ }^{22,23}$ was applied to assess the degree of functionality and activities of daily living, while the Functional Oral Intake Scale (FOIS) ${ }^{24}$ was applied for the oral food intake evaluation.

\section{Procedures}

All research tools were applied on the same day. The Alberta Stroke Program Early CT Score and Oxfordshire Community Stroke Project were scored by the same neurologist. This examiner was unaware of the data pertaining to cognitive and functional assessments.
The NIHSS, MMSE, FAB and mRS instruments were applied through interview and/or clinical examination by two trained professionals of the multidisciplinary team of the stroke unit (speech therapist and occupational therapist) with a good inter-observer statistical agreement (kappa = 0.850). The FOIS was applied by the speech therapist.

\section{Statistical analysis}

The SPSS v.20.0 program was used. Qualitative variables were described as frequencies and percentages. The continuous variables were tested for normality through the ShapiroWilk test. As the vast majority of the continuous variables did not show evidence of normal distribution, non-parametric tests were used. Spearman's correlation was employed for correlation between continuous variables. The Backward method was used for linear multivariate regression considering a p-value less than 0.20 for the entry of the covariables in the model. A bilateral p-value less than 0.05 was adopted as the statistical significance level for all tests.

\section{RESULTS}

From January to June 2015, 79 patients with a diagnosis of ischemic stroke with ictus within 24 hours were admitted at the stroke unit. Sixteen patients were excluded due to the presence of aphasia, and 63 were enrolled in this study.

Table 1 shows the sociodemographic and clinical characteristics of the population. Thirty-four (54\%) were men and the mean age of the patients was 63.6 years. The individuals had a low education level, with an average of 4.3 years of formal schooling.

Table 1. Sociodemographic and clinical characteristics of the patients.

\begin{tabular}{lcc}
\hline \multirow{2}{*}{ Variables } & \multicolumn{2}{c}{ Patients (63) } \\
\cline { 2 - 3 } & $\mathrm{n}$ & Proportion (\%) \\
\hline Gender & 34 & $(54.0)$ \\
$\quad$ Male & 29 & $(46.0)$ \\
$\quad$ Female & & \\
Age (years) & & $63.6 \pm 13.5$ \\
$\quad$ Mean \pm ASD & & $63(33--93)$ \\
$\quad$ Median (range) & & \\
Education (years) & & $4.3 \pm 3.4$ \\
$\quad$ Mean \pm ASD & & $4.0(0-12)$ \\
$\quad$ Median (range) & & \\
Work & 34 & $(54.0)$ \\
$\quad$ Active & 34 & $(54.0)$ \\
$\quad$ Previous stroke & & \\
OCSP & 35 & $(55.6)$ \\
Lacunar & 23 & $(36.5)$ \\
\hline Partial anterior circulation & 2 & $(3.2)$ \\
\hline Total anterior circulation & 3 & $(4.8)$ \\
\hline Posterior circulation & 1 & $(1.6)$ \\
\hline Thrombolysis & & \\
\hline
\end{tabular}

n: number of patients; ASD: average standard deviation; OCSP: Oxfordshire community stroke project. 
Over $90 \%$ of the patients had neurological deficits according to the NIHSS, and the mean score was compatible with a moderate impairment (4-15 points). Almost half the patients presented with alterations in brain computerized tomography scans (Table 2). More than half the patients presented with changes in general cognition, as assessed by the MMSE (68.3\%), and in executive function, as assessed by the FAB $(81 \%)$.

Table 2. Characteristics of the neurological impairment, cognitive performance and physical function of the patients.

\begin{tabular}{|c|c|c|}
\hline \multirow{2}{*}{ Variables } & \multicolumn{2}{|r|}{ Patients (63) } \\
\hline & $\mathrm{n}$ & Proportion (\%) \\
\hline \multicolumn{3}{|l|}{ ASPECTS } \\
\hline Normal & 34 & (54.0) \\
\hline Altered & 29 & (46.0) \\
\hline Mean \pm ASD & & $9.3 \pm 1.0$ \\
\hline Median (range) & & $10(5-10)$ \\
\hline \multicolumn{3}{|l|}{ NIHSS } \\
\hline Normal & 4 & (6.3) \\
\hline Altered & 59 & (93.7) \\
\hline Mean \pm ASD & & $5.2 \pm 3.8$ \\
\hline Median (range) & & $4(0-17)$ \\
\hline \multicolumn{3}{|l|}{ MMSE } \\
\hline Normal & 20 & (31.7) \\
\hline Altered & 43 & (68.3) \\
\hline Mean \pm ASD & & $21.1 \pm 5.1$ \\
\hline Median (range) & & $21(10-30)$ \\
\hline \multicolumn{3}{|l|}{ FAB } \\
\hline Normal & 12 & (19.0) \\
\hline Altered & 51 & (81.0) \\
\hline Mean \pm ASD & & $8.0 \pm 6.0$ \\
\hline Median (range) & & $7(0-18)$ \\
\hline \multicolumn{3}{|l|}{$\mathrm{mRS}$} \\
\hline Normal & 10 & (16.0) \\
\hline Altered & 53 & (84.0) \\
\hline Mean \pm ASD & & $2.1 \pm 1.3$ \\
\hline Median (range) & & $2(0-5)$ \\
\hline \multicolumn{3}{|l|}{ FOIS } \\
\hline Normal & 32 & $(50.8)$ \\
\hline Altered & 30 & $(49.2)$ \\
\hline Mean \pm ASD & & $5.9 \pm 1.3$ \\
\hline Median (range) & & $6(1-7)$ \\
\hline
\end{tabular}

Regarding functional impairment, as assessed by the mRS, most patients $(84.0 \%)$ were classified as having a slight-to-moderately-severe disability. Regarding oral food intake, half the patients had some dietary restriction: consistency, volume, and handling due to dysphagia (Table 2).

The FAB and MMSE were significantly associated with the NIHSS, mRS and FOIS (Tables 3 and 4). An adjusted R coefficient of 0.726 was found by processing the linear multivariate regression analysis, indicating that the MMSE and FOIS variables were independent and associated with executive function (Table 4).

\section{DISCUSSION}

Our results indicated that executive dysfunction was common in the acute phase of ischemic stroke, and was highly associated with impairment of general cognition and food intake.

In line with our findings, previous studies have shown that $50 \%$ of patients with stroke, regardless the severity or subtype, present with deficits in executive function ${ }^{7,8}$. Studies have already reported the correlation between executive function and motor (physical) function ${ }^{3,4,5,11}$. Our study corroborates this view and adds original information on the influence of executive function on oral food intake after stroke. No previous study had evaluated the potential association of executive function and oral food intake in stroke. Food intake impairment following stroke had been associated with spatial and time disorientation and language

Table 3. Correlations between Mini-Mental State Examination (MMSE) with other clinical instruments.

\begin{tabular}{lcc}
\hline Continuous variables & Rho & p-value \\
\hline FAB & 0.724 & $<0.001$ \\
ASPECTS & 0.214 & 0.098 \\
NIHSS & -0.391 & 0.002 \\
mRS & -0.328 & 0.009 \\
FOIS & 0.358 & 0.004 \\
\hline
\end{tabular}

ASPECTS: Alberta Stroke Program Early CT Score; NIHSS: National Institutes of Health Stroke Scale; MMSE: mini-mental state examination; FAB: frontal assessment battery; mRS: modified Rankin scale; FOIS: functional oral intake scale; Rho: Spearman's rank correlation; Test used: Spearman's rank correlation coefficient.

Table 4. Univariate and multivariate analyses of the association of the Frontal Assessment Battery (FAB) with other clinical instruments.

\begin{tabular}{lccccc}
\hline \multirow{2}{*}{ Continuous variables } & \multicolumn{5}{c}{ FAB } \\
\cline { 2 - 6 } & Rho & p-value* & Coefficient B & p-value** & Confidence interval 95\% \\
\hline MMSE & 0.724 & $<0.001$ & 0.452 & $<0.001$ & $0.276-0.629$ \\
ASPECTS & 0.284 & 0.027 & -0.221 & 0.578 & $-0.840-2.006$ \\
NIHSS & -0.448 & $<0.001$ & -0.129 & 0.242 & $-0.565-0.086$ \\
mRS & -0.263 & 0.037 & 0.629 & 0.073 & $-0.655-1.422$ \\
FOIS & 0.811 & $<0.001$ & 2.254 & $<0.001$ & $1.697-2.811$
\end{tabular}

ASPECTS: Alberta Stroke Program Early CT Score; NIHSS: National Institutes of Health Stroke Scale; MMSE: mini-mental state examination; FAB: frontal assessment battery; mRS: modified rankin scale; FOIS: functional oral intake scale; Rho: Spearman's rank correlation; Test used: Spearman's rank correlation coefficient*; Linear multivariate regression analysis**. 
disorders ${ }^{11,12}$. In other neurological diseases, mainly neurodegenerative diseases, changes in executive function have been implicated in complications related to swallowing ${ }^{16,17}$.

It is well known that swallowing consists of intrinsically-related stages divided into anticipatory, preparatory, oral, pharyngeal and esophageal. While the first three stages are considered voluntary, the remaining two are involuntary. Although swallowing is primarily mediated by the structures of the brainstem, multiple cerebral cortex regions play a key role in its regulation ${ }^{25,26}$. Indeed, functional magnetic resonance studies suggest multiple cortical representation in the swallowing process, including the prefrontal cortices implicated in executive functions ${ }^{25}$. Accordingly, our study suggests a role of executive function in oral food intake after stroke.

Our study has several limitations that must be considered. We could not establish a cause-effect relationship between the variables, due to the cross-sectional nature of the study. The current study indicates a significant association between executive function and food intake, possibly suggesting a role of executive function in swallowing control in acute ischemic stroke. However, future longitudinal studies are necessary to confirm this assumption. Another limitation is the absence of data on the previous cognitive performance of the patients. Although patients with past neurological diagnoses, including dementia, were excluded, it was not possible to completely rule out previous subclinical cognitive and/or executive dysfunction. As we also excluded patients with aphasia due to its influence on cognitive tests that are based on verbal skills, patients with right hemisphere lesions were overrepresented in our sample, limiting the generalizability of the current findings. It is worth mentioning that laterality may affect the efficiency of cognitive functions ${ }^{27}$. Formal education is an important variable to be considered in the evaluation of cognitive functions, especially in the elderly population ${ }^{18-20}$. The low educational level of our sample is a striking feature. In this regard, our sample significantly differs from stroke studies carried out in Europe and North America. Conversely, it is in line with neuroepidemiological studies from Brazil and other developing coun$\operatorname{tries}^{27,28}$. This aspect highlights the need for local studies, and a more critical view of overseas studies.

In conclusion, oral food intake is influenced by executive function in the acute phase of ischemic stroke.

\section{References}

1. Papazian O, Alfonso I. luzondo, RJ. Trastornos de las funciones ejecutiva. Rev Neurol. 2006;42(3):45-50.

2. Nys GM, Zandvoort MJ, Kort PL, Jansen BP, Haan EH, Kappelle LJ. Cognitive disorders in acute stroke: prevalence and clinical determinants. Cerebrovasc Dis. 2007;23(5-6):408-16. https://doi.org/10.1159/000101464

3. Hayes S, Donnellan C, Stokes E. Associations between executive function and physical function poststroke: a pilot study. Physiotherapy. 2013 Jun;99(2):165-71. https://doi.org/10.1016/j.physio.2012.05.002

4. Silva JM, Hasse HK, Yussef SM, Kaminski LE. Efeitos da dupla tarefa com demanda motora e demanda cognitiva na marcha de sujeitos hemiparéticos pós AVC. Rev Neurocienc. 2015;23(1):48-54.

5. Rasquin SM, Verhey FR, Lousberg R, Lodder J. Cognitive performance after first ever stroke related to progression of vascular brain damage: a 2 year follow up CT scan study. J Neurol Neurosurg Psychiatry. 2005 Aug;76(8):1075-9. https://doi.org/10.1136/jnnp.2004.055541

6. Benge JF, Caroselli JS, Temple RO. Wisconsin Card Sorting Test: factor structure and relationship to productivity and supervision needs following severe traumatic brain injury. Brain Inj. 2007 Apr;21(4):395-400. https://doi.org/10.1080/02699050701311091

7. Zinn S, Bosworth HB, Hoenig HM, Swartzwelder HS. Executive function deficits in acute stroke. Arch Phys Med Rehabil. 2007 Feb;88(2):173-80. https://doi.org/10.1016/j.apmr.2006.11.015

8. Jodzio K, Biechowska D. Wisconsin card sorting test as a measure of executive function impairments in stroke patients. Appl Neuropsychol. 2010 Oct;17(4):267-77. https://doi.org/10.1080/09084282.2010.525104

9. Hayes S, Donnellan C, Stokes E. The measurement and impairment of executive function after stroke and concepts for physiotherapy: a review. Phys Ther. 2011;16(3):178-90. https://doi.org/10.1179/1743288X11Y.0000000030
10. Coppin AK, Shumway-Cook A, Saczynski JS, Patel KV, Ble A, Ferrucci L et al. Association of executive function and performance of dual-task physical tests among older adults: analyses from the InChianti study. Age Ageing. 2006 Nov;35(6):619-24. https://doi.org/10.1093/ageing/afl107

11. Costa FA, Silva DL, Rocha VM. The neurological state and cognition of patients after a stoke. Rev Esc Enferm USP. 2011 Oct;45(5):1083-8. https://doi.org/10.1590/S0080-62342011000500008

12. Leder SB, Suiter DM, Lisitano Warner H. Answering orientation questions and following single-step verbal commands: effect on aspiration status. Dysphagia. 2009 Sep;24(3):290-5. https://doi.org/10.1007/s00455-008-9204-x

13. Yew KS, Cheng E. Acute stroke diagnosis. Am Fam Physician. 2009 Jul:80(1):33-40

14. Carod-Artal FJ, Trizotto DS, Coral LF, Moreira CM. Determinants of quality of life in Brazilian stroke survivors. J Neurol Sci. 2009 Sep;284(1-2):63-8. https://doi.org/10.1016/j.jns.2009.04.008

15. O’Brien JT, Erkinjuntti T, Reisberg B, Roman G, Sawada T, Pantoni L et al. Vascular cognitive impairment. Lancet Neurol. 2003 Feb;2(2):89-98. https://doi.org/10.1016/S1474-4422(03)00305-3

16. Rivière S, Gillette-Guyonnet S, Andrieu S, Nourhashemi F, Lauque $S$, Cantet $\mathrm{C}$ et al. Cognitive function and caregiver burden: predictive factors for eating behaviour disorders in Alzheimer's disease. Int J Geriatr Psychiatry. 2002 Oct;17(10):950-5. https://doi.org/10.1002/gps.724

17. Priefer BA, Robbins J. Eating changes in mild-stage Alzheimer's disease: a pilot study. Dysphagia. 1997;12(4):212-21. https://doi.org/10.1007/PL00009539

18. Brucki SM, Nitrini R, Caramelli P, Bertolucci PH, Okamoto IH. [Suggestions for utilization of the mini-mental state examination in Brazil]. Arq Neuropsiquiatr. 2003;61(3B):777-81. Portuguese. https://doi.org/10.1590/S0004-282X2003000500014 
19. Beato RG, Nitrini R, Formigoni AP, Caramelli P. Brazilian version of the Frontal Assessment Battery (FAB): preliminary data on administration to healthy elderly. Dement Neuropsychol. 2007 Jan-Mar;1(1):59-65. https://doi.org/10.1590/S1980-57642008DN10100010

20. Coelho FG, Vital TM, Novais IP, Costa GA, Stella F, Santos-Galduroz RF. Desempenho cognitivo em diferentes níveis de escolaridade de adultos e idosos ativos. Rev Bras Geriatr Gerontol. 2012;15(1):7-15. https://doi.org/10.1590/S1809-98232012000100002

21. Barber M, Langhorne P, Rumley A, Lowe GD, Stott DJ. Hemostatic function and progressing ischemic stroke: $d$-dimer predicts early clinical progression. Stroke. 2004 Jun;35(6):1421-5. https://doi.org/10.1161/01.STR.0000126890.63512.41

22. Cincura C, Pontes-Neto OM, Neville IS, Mendes HF, Menezes DF, Mariano DC et al. Validation of the National Institutes of Health Stroke Scale, modified Rankin Scale and Barthel Index in Brazil: the role of cultural adaptation and structured interviewing. Cerebrovasc Dis. 2009;27(2):119-22. https://doi.org/10.1159/000177918

23. Haan R, Limburg M, Bossuyt P, Meulen J, Aaronson N. The clinical meaning of Rankin ‘handicap' grades after stroke. Stroke. 1995 Nov;26(11):2027-30. https://doi.org/10.1161/01.STR.26.11.2027
24. Crary MA, Mann GD, Groher ME. Initial psychometric assessment of a functional oral intake scale for dysphagia in stroke patients. Arch Phys Med Rehabil. 2005 Aug;86(8):1516-20. https://doi.org/10.1016/j.apmr.2004.11.049

25. Malandraki GA, Johnson S, Robbins J. Functional magnetic resonance imaging of swallowing function: from neurophysiology to neuroplasticity. Head Neck. 2011;33 Suppl 1:S14-20. https://doi.org/10.1002/hed.21903

26. Babaei A, Ward BD, Siwiec RM, Ahmad S, Kern M, Nencka A et al. Functional connectivity of the cortical swallowing network in humans. Neuroimage. 2013 Aug;76(1):33-44. https://doi.org/10.1016/j.neuroimage.2013.01.037

27. Ocklenburg S, Hirnstein M, Beste C, Güntürkün O. Lateralization and cognitive systems. Front Psychol. 2014 Oct;5:1143. https://doi.org/10.3389/fpsyg.2014.01143

28. Caramelli P, Barbosa MT, Sakurai E, Dos Santos EL, Beato RG, Machado JC et al.; Pietà Study Group. The Pietà study: epidemiological investigation on successful brain aging in Caeté (MG), Brazil. Methods and baseline cohort characteristics. Arq Neuropsiquiatr. 2011 Aug;69(4):579-84. https://doi.org/10.1590/S0004-282X2011000500002 


\section{Erratum}

Arq Neuropsiquiatr 2018;76(3):158-162. DOI: https://doi.org/10.1590/0004-282X20180005

\section{The name of the authors:}

Mourão, Aline Mansueto; Vicente, Laélia Cristina Caseiro; Abreu, Mery Natali Silva; Chaves, Tatiana Simões; Sant'Anna, Romeu Vale; Braga, Marcela Aline Fernandes; Meira, Fidel Castro Alves de; Souza, Leonardo Cruz de; Miranda, Aline Silva de; Rachid, Milene Alvarenga; Teixeira, Antônio Lucio

\section{Should be:}

Mourão, Aline Mansueto; Vicente, Laélia Cristina Caseiro; Abreu, Mery Natali Silva; Chaves, Tatiana Simões; Sant’Anna, Romeu Vale; Braga, Marcela Aline Fernandes; Meira, Fidel Castro Alves de; de Souza, Leonardo Cruz; Miranda, Aline Silva de; Rachid, Milene Alvarenga; Teixeira, Antônio Lucio 